\title{
Lysosomal enzyme cytochemistry in acute leukaemia
}

\author{
J. R. MANN, J. S. SIMPSON, R. M. MUNKLEY, AND J. STUART \\ From the Department of Haematology, The Children's Hospital, Birmingham
}

SYNOPSIS A cytochemical study of the lysosomal enzyme $\beta$-glucuronidase in 60 cases of acute leukaemia has shown a qualitative difference in the cytoplasmic distribution of the enzyme between blast cells of the lymphoid and myeloid cell series. This difference provides a useful additional method for cytochemical classification of cell type and is superior in this respect to the other lysosomal enzymes studied (aryl sulphatase and acid phosphatase). The $\beta$-glucuronidase reaction is recommended in those cases of acute leukaemia in which the periodic acid-Schiff reaction is negative or equivocal.

The periodic acid-Schiff (PAS), Sudan Black, and peroxidase cytochemical reactions give rise to coloured reaction end products which show characteristic qualitative and quantitative differences between mature cells of the myeloid and lymphoid series. In precursor, or blast, cells these characteristic differences are less obvious but essentially still hold true (Hayhoe, Quaglino, and Doll, 1964), and the application of these techniques has given rise to greater uniformity in the classification of the acute leukaemias by providing morphological criteria which are more easily recognized than those of a simple Romanowsky stain.

A practised observer can probably classify at least $90 \%$ of acute leukaemias using these techniques; in the remainder, the diagnosis is difficult because the reactions are either negative or are weakly positive in such a small percentage of cells (less than $5 \%$ ) that doubt arises as to the nature of the reaction and the identity of the cells. Since mature cells of the myeloid series are characterized by numerous granules which are predominantly lysosomal in nature, and since lymphoid cells contain relatively few lysosomes, it would seem logical that a cytochemical study of lysosomal enzymes at the blast cell stage of maturation might also give rise to morphological differences between the two cell lines. A cytochemical study has therefore been maude of the lysosomal enzymes $\beta$-glucuronidase $(\beta$-Dglucuronide glucuronohydrolase), aryl sulphatase (aryl-sulphate sulphohydrolase), and acid phosphatase (orthophosphoric monoester phosphohydrolase) in order to define those characteristics which identify the myeloid and lymphoid cell lines at the blast cell stage of development.

Received for publication 24 March 1971.

\section{Methods}

\section{$\beta$-GLUCURONIDASE}

The method used was based on the simultaneous coupling method of Hayashi, Nakajima, and Fishman (1964), also used by Lorbacher, Yam, and Mitus (1967), employing naphthol AS-BI- $\beta$-Dglucosiduronic acid as substrate and hexazonium pararosaniline as coupling agent. The method was modified as follows: (1) air dry films for at least 60 $\mathrm{min}$ at room temperature; (2) incubate for $120 \mathrm{~min}$ at $37^{\circ} \mathrm{C}$ in freshly prepared incubation medium; (3) wash gently in running tap water for five min, and (4) air dry. The incubation medium was prepared according to Hayashi et al (1964) and the pararosaniline solution according to Barka and Anderson (1962). The stock solution of naphthol AS-BI glucuronide (free acid) was stable at $0-4^{\circ} \mathrm{C}$ for two to three months; the pale yellow working solution was made up immediately before use and did not require to be filtered. The specificity of the reaction was confirmed by its abolition when the specific inhibitor D-gluco-saccharolactone was incorporated in the incubation medium at a concentration of $2 \cdot 3 \mathrm{~g} / 100 \mathrm{ml}$.

\section{ARYL SULPHATASE}

The method used was based on that of Austin and Bischel (1961) using potassium 6-benzoyl-2-naphthol sulphate as substrate and Fast Blue RR as coupling agent. The following modifications were made: films were air dried for at least $60 \mathrm{~min}$, then fixed in $100 \%$ acetone at room temperature for $60 \mathrm{sec}$, followed by immersion in $5 \%$ polyvinylpyrrolidone for $60 \mathrm{sec}$ (Melnick, 1968); Fast Blue RR was used at a concentration of $0.3 \mathrm{mg} / \mathrm{ml}$; and the incubation period 
was reduced to 24 hours. The nature and distribution of the reaction end-product was similar using $100 \%$ acetone as fixative compared with unfixed films, although cellular preservation was considerably enhanced, and the characteristic unstained nucleus of mature myeloid cells (Lawrinson and Gross, 1964) was retained.

\section{ACID PHOSPHATASE}

The two principal methods for the demonstration of acid phosphatase activity were studied: the simultaneous coupling azo-dye method employing naphthol (or substituted naphthol) phosphate as substrate and the lead-salt technique originally described by Gomori (1952).

A number of azo-dye techniques (Goldberg and Barka, 1962; Rozenszajn, Marshak, and Efrati, 1963; Kaplow and Burstone, 1964; Rosales, Bennett, and Rutenburg, 1966) were studied using several different fixatives and also using unfixed cells. The most intense and reliable reaction was obtained using naphthol AS phosphate as substrate and Fast Blue BB as coupling salt (Rosales et al, 1966); the method was modified by omitting the fixative, which resulted in a stronger reaction end-product, although some cells were lost from the smears. The nature of the reaction end-product with these techniques was always granular or crystalline in appearance with no significant cytoplasmic diffusion.

The original Gomori lead-salt method was criticized on account of non-specific artifactual staining of the nucleus, but this has been overcome by careful control of the concentration of lead ions in the incubation solution (Holt, 1959). A method utilizing lead acetate in place of lead nitrate (Lake, 1966), the acetate ion causing less enzyme inhibition, was modified as follows: (1) air dry films for at least $60 \mathrm{~min}$ at room temperature; (2) incubate unfixed films in freshly prepared and filtered incubation medium for $90 \mathrm{~min}$ at $37^{\circ} \mathrm{C}$; (3) wash gently in running tap water for $10 \mathrm{~min}$; (4) develop in freshly prepared, $p \mathrm{H} 7 \cdot 0-8 \cdot 0$, dilute ammonium sulphide for five sec; (5) wash gently in running tap water for $10 \mathrm{~min}$, then counterstain with methyl green.

\section{Incubation medium}

Dissolve $31.4 \mathrm{mg}$ sodium $\beta$-glycerophosphate in $5 \mathrm{ml}$ $0 \cdot 1 \mathrm{M}$ acetate buffer, $p \mathrm{H} 5 \cdot 0$, and add $5 \mathrm{ml}$ of $0.008 \mathrm{M}$ lead acetate. Shake well and filter on to slides.

\section{Ammonium sulphide solution}

Prepare an aqueous solution of sodium dihydrogen orthophosphate to a concentration of $83 \mathrm{mg} /$ litre. Immediately before use add, to $50 \mathrm{ml}$ of this, 6-7 drops of concentrated ammonium sulphide (using a fume cupboard) to give a final $p \mathrm{H}$ of $7 \cdot 0$ to $8 \cdot 0$.
Acid phosphatase activity was demonstrated by the presence of brown cytoplasmic granules with a small amount of diffusion in the proximity of each $\stackrel{5}{\leftrightarrows}$ granule; there was no artificial crystalline appear- $\bar{D}$ ance of the reaction end-product, as seen with some 흘 azo-dye techniques, and nuclear activity was not $\frac{\bar{m}}{7}$ observed. The reaction intensity was comparable to $\stackrel{\mathbb{D}}{\Omega}$ the best of the azo-dye techniques.

PAS, SUDAN BLACK, AND PEROXIDASE

REACTIONS

As a basis for evaluation of lysosomal enzyme cytochemistry an attempt was made to classify all bone $\overline{0}$ marrow specimens as lymphoblastic or myeloblastic i (incorporating myelomonocytic) using the methods $\stackrel{+}{i 0}$ and criteria for the PAS, Sudan Black, and peroxidase ${ }^{\circ}$ reactions as described by Hayhoe et al (1964).

\section{$\beta$-GLUCURONIDASE}

A qualitative difference in the nature of the reaction end-product was noted in myeloid compared with lymphoid cells. In mature lymphocytes and in 3 lymphoblasts the $\beta$-glucuronidase activity was restricted to a solitary block, or to several large granules but without generalized diffusion throughout the cytoplasm (Fig. 1). Localized diffusion in the areaof each block or granule was sometimes seen. In myeloid cells the reaction end-product was dis-乏̧ tributed diffusely throughout the cytoplasm, sometimes with superimposed granules (Fig. 2); this气 pattern was seen at all stages of maturation with the $\stackrel{\mathbb{\Omega}}{\mathbb{Q}}$ greatest reaction intensity occurring at the meta- $\overrightarrow{\vec{A}}$ myelocyte stage of differentiation. No distinction could be made between myeloid precursors and monocytes since diffusion was seen in both.

A semi-quantitative scoring technique was used to compare the granular and diffuse positivity in? myeloblasts compared with lymphoblasts in 43 cases of acute leukaemia which had previously been classified without difficulty according to the PAS, Sudano Black, and peroxidase reactions:

$$
\begin{aligned}
\text { Granules }-0 & =\text { Nil } \\
1= & 1-10 \text { small granules } \\
2= & 1-10 \text { medium granules } \\
3= & >10 \text { small or medium granules or } \\
& \text { any number of blocks } \\
\text { Diffusion- } 0= & \text { Nil } \\
1= & \text { weak and restricted to the areac } \\
& \text { around individual granules } \\
= & \text { moderate diffusion throughout the } \\
& \text { cytoplasm } \\
3= & \text { strong diffusion throughout the } \\
& \text { cytoplasm }
\end{aligned}
$$

The individual scores for granular and diffuse positivity are shown in Table I. A significant increase? $(\mathrm{P}<0.01)$ in the amount of cytoplasmic diffusion 


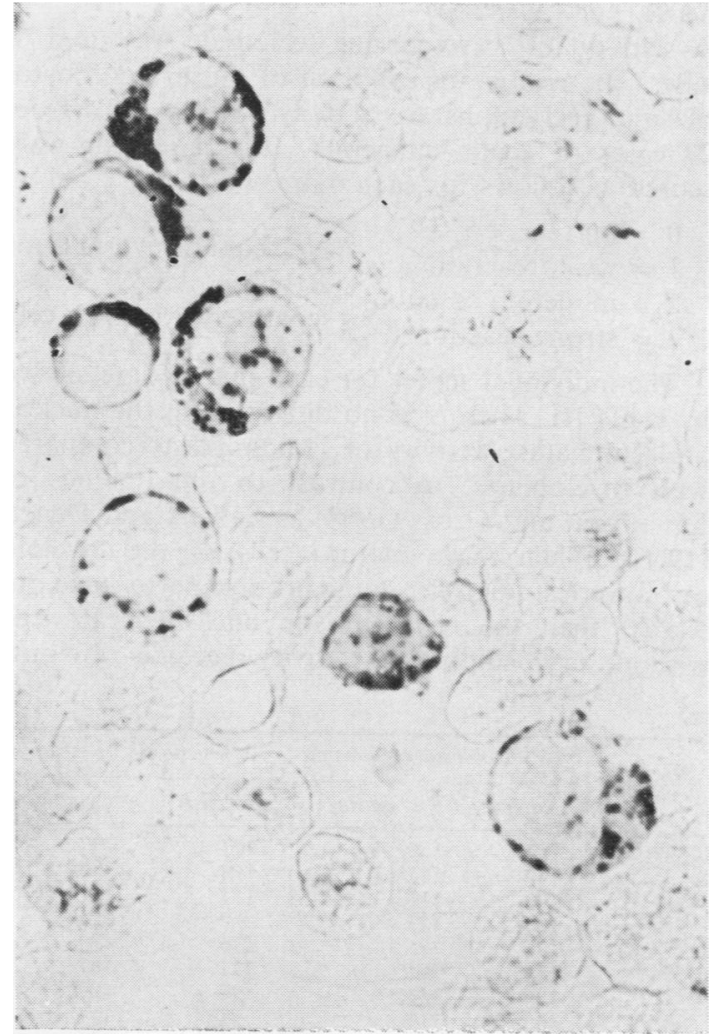

Fig. 1.

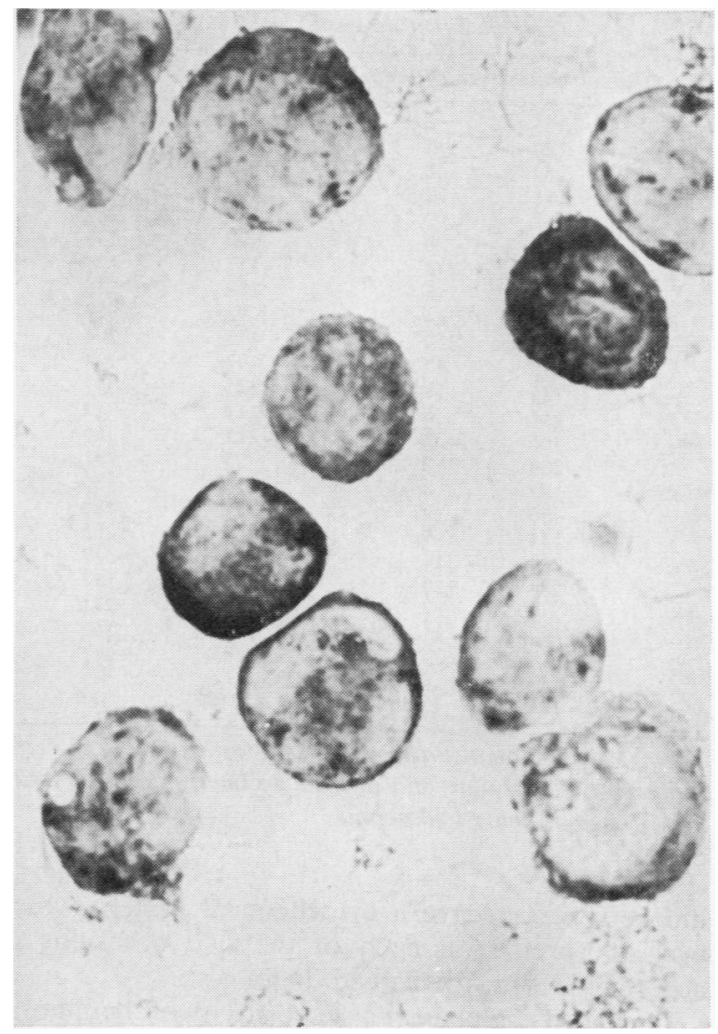

Fig. 2.

Fig. 1 Strong, localized, granular $\beta$-glucuronidase positivity in acute lymphoblastic leukaemia. This represents an unusually strong reaction selected for photographic purposes. No nuclear counterstain. $\times 1,600$ Fig. 2 Diffuse cytoplasmic $\beta$-glucuronidase activity in acute myeloblastic leukaemia. No nuclear counterstain.
$\times 1,600$

was found in myeloblasts compared with lymphoblasts.

In order to assess the diagnostic accuracy of the $\beta$-glucuronidase reaction in differentiating between the lymphoblast and the myeloblast, 60 sequential acute leukaemia marrows (29 lymphoblastic and 31 myeloblastic, or myelomonocytic) from both children and adults were studied. One additional case, of lymphosarcoma cell leukaemia, was excluded. In each case a cytochemical classification was attempted by means of the PAS, Sudan Black, and peroxidase reactions; where difficulty was experienced in this a second opinion was sought and a subsequent relapse marrow was studied where possible. The number of remissions and/or duration of survival were also used as supportive evidence before an agreed diagnosis of the type of leukaemia was made.
For each marrow studied the PAS and $\beta$-glucuronidase slides were then masked and numbered; each slide was examined on two separate occasions and a diagnosis of 'lymphoblastic' or 'myeloblastic' or 'uncertain' made from it on each occasion. In six cases the diagnosis made from the PAS reaction alone was 'uncertain' on one of the two occasions. This arose due to a negative, or a near-negative, reaction (see Table II). When the coded $\beta$-glucuronidase slides were studied alone then an 'uncertain' or a conflicting diagnosis was made in five cases: in four of the cases this occurred because the lack of a counterstain hindered the correct identification of blast cells. In the remaining case (G.A.-Table II) a false diagnosis of myeloblastic leukaemia was made due to the presence of numerous blocks or large granules in the blast cells simulating a confluent diffuse pattern. In the other 55 cases the $\beta$-glucuro- 


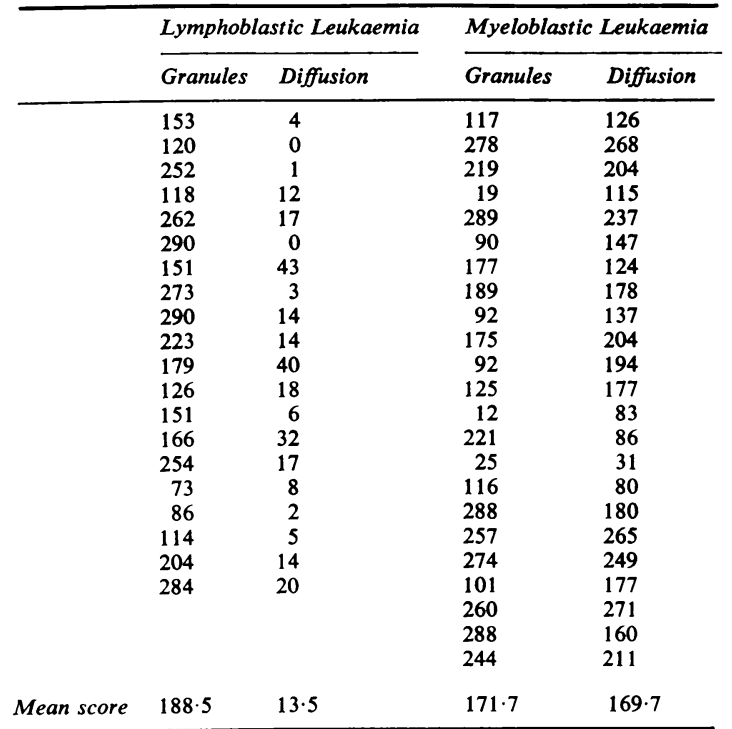

Table I Semi-quantitative scores (for 100 blast cells) representing granular and diffuse $\beta$-glucuronidase activity in 43 cases of acute leukaemia

nidase reaction gave a cytochemical pattern which was interpreted on each of the two occasions in accordance with the agreed diagnosis.

Localized $\beta$-glucuronidase positivity of 'lymphoid' type was also found in the lymphocyte of chronic lymphocytic leukaemia, in the PHA-transformed lymphocyte, and in the majority of atypical mononuclears of Paul-Bunnell-positive mononucleosis.

The enzyme was found to be relatively stable and showed no demonstrable loss of activity when marrow films were stored for seven days at room temperature or at $4^{\circ} \mathrm{C}$. No enhancement of the reaction was obtained by refrigeration of the films at $-20^{\circ} \mathrm{C}$ in order to increase lysosomal membrane permeability to substrate (Lorbacher et al, 1967).
ARYL SULPHATASE

A semi-quantitative scoring technique was used to assess the relative distribution of nuclear and cytoplasmic aryl sulphatase activity in blast cells from 28 cases of acute leukaemia. 100 blast cells were scored as follows for each marrow:

$0=$ no reaction

$1=$ weak reaction

$2=$ moderate reaction

$3=$ strong reaction

Nuclear and cytoplasmic $\nRightarrow$ activities were scored separately for each cell.

The individual scores for each marrow are shown in Table III. There was no difference in the nuclear aryl sulphatase activity of lymphoblasts compared with myeloblasts, in contrast to the findings of Lawrinson and Gross (1964) and Ekert and Denett (1966). When more mature cells of the myeloid series were studied (from the promyelocyte stage onwards) then the characteristic nuclear clear area without aryl sulphatase activity became obvious;

\begin{tabular}{|c|c|c|c|c|}
\hline & \multicolumn{2}{|c|}{ Lymphoblastic Leukaemia } & \multicolumn{2}{|c|}{ Myeloblastic Leukaemia } \\
\hline & Nucleus & Cytoplasm & Nucleus & Cytoplasm \\
\hline & 99 & 158 & 197 & 197 \\
\hline & 140 & 184 & 109 & 195 \\
\hline & 100 & 110 & 181 & 191 \\
\hline & 100 & 112 & 90 & 203 \\
\hline & 185 & 195 & 176 & 199 \\
\hline & 188 & 201 & 111 & 187 \\
\hline & 100 & 150 & 96 & 100 \\
\hline & 100 & 110 & 97 & 114 \\
\hline & 101 & 110 & 100 & 131 \\
\hline & 187 & 191 & 99 & 119 \\
\hline & 111 & 115 & 237 & 267 \\
\hline & 140 & 177 & & \\
\hline & 99 & 93 & & \\
\hline & 188 & 199 & & \\
\hline & 139 & 163 & & \\
\hline & 101 & 101 & & \\
\hline & 185 & 191 & & \\
\hline Mean score & $133 \cdot 1$ & $150 \cdot 6$ & $135 \cdot 7$ & $173 \cdot 0$ \\
\hline
\end{tabular}

Table III Semi-quantitative scores (for 100 blast cells) representing nuclear and cytoplasmic aryl sulphatase activity in 28 cases of acute leukaemia

\begin{tabular}{|c|c|c|c|c|c|}
\hline Patient & $\begin{array}{l}\text { Age } \\
\text { (Years) }\end{array}$ & $\begin{array}{l}\text { Agreed } \\
\text { Diagnosis }\end{array}$ & $\begin{array}{l}\beta \text {-Glucuronidase } \\
\text { Reaction }\end{array}$ & PAS Reaction & Main Criteria for Agreed Diagnosis \\
\hline $\begin{array}{l}\text { M.M. } \\
\text { K.C. } \\
\text { J.B. } \\
\text { G.A. } \\
\text { R.D. } \\
\text { B.K. } \\
\text { A.O. } \\
\text { R.H. } \\
\text { J.F. }\end{array}$ & $\begin{array}{r}14 \\
10 \\
12 \\
9 \\
2 \\
55 \\
58 \\
76 \\
37\end{array}$ & $\begin{array}{l}\text { A.L.L. } \\
\text { A.L.L. } \\
\text { A.L.L. } \\
\text { A.L.L. } \\
\text { A.L.L. } \\
\text { A.L.L. } \\
\text { A.M.L. } \\
\text { A.M.L. } \\
\text { A.M.L. }\end{array}$ & $\begin{array}{l}\text { Lymphoid pattern } \\
\text { Lymphoid pattern } \\
\text { Lymphoid pattern } \\
\text { Myeloid pattern } \\
\text { Uncertain } \\
\text { Uncertain } \\
\text { Myeloid pattern } \\
\text { Uncertain } \\
\text { Uncertain }\end{array}$ & $\begin{array}{l}\text { Negative } \\
\text { Uncertain } \\
\text { Uncertain } \\
\text { Lymphoid pattern } \\
\text { Lymphoid pattern } \\
\text { Lymphoid pattern } \\
\text { Negative } \\
\text { Uncertain } \\
\text { Uncertain }\end{array}$ & $\begin{array}{l}\text { PAS lymphoid pattern in relapse marrow } \\
\text { PAS lymphoid pattern in } 1 \% \text { of blasts } \\
\text { The same as in K.C. } \\
\text { PAS lymphoid pattern and first remission of } 2 \text { years } \\
\text { PAS lymphoid pattern } \\
\text { The same as in R.D. } \\
\text { Sudan Black localized positivity } \\
\text { PAS myeloid pattern in } 4 \% \text { of blasts } \\
\text { The same as in R.H. }\end{array}$ \\
\hline
\end{tabular}

Table II Clinical and cytochemical data for the nine cases of acute leukaemia where the masked slide for either the $\beta$-glucuronidase or the PAS reaction did not give a cytochemical diagnosis in accordance with the previously agreed (A.L.L. or A.M.L.) diagnosis

'Uncertain' represents an inability to reach a firm diagnosis due to a weak reaction or to uncertainty in the recognition of blast cells. The agreed diagnosis was based on cytochemical and clinical evidence (see Methods): the most important cytochemical criterion used to reach the agreed diagnosis in each case is given in the table. 
at the blast cell stage of differentiation there was usually sufficient nuclear staining in myeloblasts to invalidate clear differentiation from lymphoblasts. The use of fixatives containing as little as $1 \%$ formaldehyde solution failed to maintain the nuclear/cytoplasmic differentiation even in mature myeloid cells. The presence of nuclear aryl sulphatase activity in myeloblasts has also been demonstrated by Smutka and Brunning (1969) using $2 \%$ glutaraldehyde as a fixative.

\section{ACID PHOSPHATASE}

The semi-quantitative scoring technique of Rozenszajn et al (1963) was used to assess the number and size of granules denoting Gomori-type acid phosphatase activity in marrow blast cells from 27 cases of acute leukaemia. While the mean score obtained for myeloblasts was more than twice that obtained for lymphoblasts (Table IV) there was obvious overlap when individual marrow scores were studied. Since no qualitative difference was detected in the nature of the reaction end-product in myeloblasts compared with lymphoblasts, and since differentiation on a quantitative basis did not distinguish absolutely between the two cell types, the acid phosphatase reaction would not appear to be a valuable method for cytochemical differentiation. A similar result was obtained when the azo-dye techniques were studied.

\begin{tabular}{|c|c|c|c|}
\hline & \multicolumn{2}{|c|}{ Lymphoblastic Leukaemia } & $\frac{\text { Myeloblastic Leukaemia }}{161}$ \\
\hline & $\begin{array}{r}111 \\
31 \\
45 \\
65 \\
238 \\
61 \\
220 \\
85 \\
162\end{array}$ & $\begin{array}{r}129 \\
237 \\
55 \\
15 \\
36 \\
21 \\
22 \\
40 \\
106\end{array}$ & $\begin{array}{r}161 \\
314 \\
250 \\
205 \\
96 \\
343 \\
277 \\
206 \\
141\end{array}$ \\
\hline Mean score & \multicolumn{2}{|c|}{$93 \cdot 3$} & $221 \cdot 4$ \\
\hline
\end{tabular}

Table IV Semi-quantitative granule scores (for 100 blast cells) representing Gomori-type acid phosphatase activity in 27 cases of acute leukaemia

\section{Discussion}

The distribution of the reaction end-product when lysosomal enzymes are studied cytochemically is to some extent artifactual, being determined by the extent of cellular disruption, the effects of a fixative, the osmotic effect of the incubation solution, the speed of the coupling reaction, and the physical characteristics of the reaction end-product. In addition, the extent to which the lysosomal membranes remain intact will determine the intensity of the reaction and, to some extent, its distribution. In this respect the osmotic disruptive effect of a particular reaction incubation medium may be a more important determining factor of a characteristic reaction end-product than the actual lysosomal enzyme studied.

It is not clear why the $\beta$-glucuronidase reaction end-product diffuses throughout the cell cytoplasm in myeloid cells while remaining in large granules or blocks in lymphoid cells; this is not merely a consequence of an increased reaction intensity in myeloid cells since weak diffusion may occur in myeloblasts in the absence of granules and large blocks may be seen in lymphoblasts in the absence of diffusion. It may, however, be the result of increased solubility and subsequent diffusion of the reaction end-product in myeloid cells, perhaps as a consequence of an increased lipid content compared with lymphoid cells. A similar differential distribution is seen with the PAS reaction, but the specificity of the individual reactions can be confirmed by the use of saccharolactone in the case of $\beta$-glucuronidase and amylase in the case of glycogen. Also, in many of the lymphoblastic leukaemia marrows, a strong $\beta$-glucuronidase reaction was obtained in the majority of blast cells, whereas PAS-positive blocks were seen in only the occasional cell.

When the Sudan Black and peroxidase reactions are negative and the PAS reaction is either negative or equivocal, then the leukaemia may be labelled as stem-cell or undifferentiated in type on the assumption that the cells are too immature to accumulate sufficient glycogen, etc. This would not be a valid conclusion if glycogen were depleted as a result of active glycolysis, and it is in these circumstances that a reaction for a lysosomal enzyme is likely to be of value. Of the three enzymes studied, only the aryl sulphatase and $\beta$-glucuronidase reactions provide a qualitative difference between the myeloid and lymphoid cell lines. There is increasing evidence, from our own observations and those of Boysen (1969) and Smutka and Brunning (1969), that this distinction is often not maintained with the aryl sulphatase reaction, despite modification of the method with a variety of fixatives. In our experience, the $\beta$-glucuronidase reaction allows the distinction to be made in a high percentage of cases, although a further refinement of the method, incorporating a suitable counterstain and fixative, would be desirable. We have not been able to achieve this using a variety of counterstains and fixatives without either obscuring the red reaction product or inhibiting the enzyme. The addition to the incubation medium of polyvinyl alcohols and sucrose polymers, which appear to have a stabilizing effect on cell membranes (Stuart and Simpson, 1970), resulted in loss of the 
reaction product, even at low concentrations of $5 \% \mathrm{w} / \mathrm{v}$, probably by 'stabilizing' the lysosomal membrane to an extent that substrate permeability was substantially reduced.

The $\beta$-glucuronidase reaction is therefore recommended in those circumstances where a clear-cut cytochemical classification is not provided by the PAS, Sudan Black, and peroxidase reactions. In this event, localized $\beta$-glucuronidase positivity is indicative of the lymphoid cell line whereas diffusion throughout the cytoplasm is characteristic of myeloid (including monocytic) cells.

We are indebted to the Leukaemia Research Fund and the United Birmingham Hospitals Endowment Research Fund for financial support, and to the following haematologists who made available bone marrow specimens: W. S. A. Allan, G. P. Clein, D. I. K. Evans, I. D. O. Frew, P. Kidd, J. J. Kramer, M. J. Meynell, A. Pollock, R. H. B. Protheroe, N. K. Shinton, and D. G. Wells.

A section of this work was presented at the 6th International Meeting of the Reticuloendothelial Society, Freiburg, 1970.

\section{References}

Austin, J. H., and Bischel, M. (1961). A histochemical method for sulfatase activity in hemic cells and organ imprints. Blood, 17, 216-224.

Barka, T., and Anderson, P. J. (1962). Histochemical methods for acid phosphatase using hexazonium pararosanilin as coupler. J. Histochem. Cytochem., 10, 741-753.

Boysen, G. (1969). An evaluation of aryl sulphatase activity in leukaemic cells. Scand. J. Haemat., 6, 246-249.

Ekert, H., and Denett, X. (1966). An evaluation of nuclear aryl sulphatase activity as an aid to the cytological diagnosis of acute leukaemia. Aust. Ann. Med., 15, 152-156.

Goldberg, A. F., and Barka, T. (1962). Acid phosphatase activity in human blood cells. Nature, 195, 297.

Gomori, G. (1952). Microscopic Histochemistry. University Press, Chicago.

Hayashi, M., Nakajima, Y., and Fishman, W. H. (1964). The cytologic demonstration of $\beta$-glucuronidase employing naphthol AS-BI glucuronide and hexazonium pararosanilin; a preliminary
report. J. Histochem. Cytochem., 12, 293-297.

Hayhoe, F. G. J., Quaglino, D., and Doll, R. (1964). The Cytology and $\vec{P}$ Cytochemistry of Acute Leukaemias. Medical Research Council, Special Report Series, No. 304.

Holt, S. J. (1959). Factors governing the validity of staining methods for enzymes, and their bearing upon the Gomori acid phosphat ase technique. Exp. Cell Res., Suppl., 7, 1-27.

Kaplow, L. S., and Burstone, M. S. (1964). Cytochemical demonstration of acid phosphatase in hematopoietic cells in health and in various hematological disorders using azo dye techniques. J. Histochem. Cytochem., 12, 805-811.

Lake, B. D. (1966). The histochemistry of phosphatases: the use of lead acetate instead of lead nitrate. J. roy. micr. Soc., 85, 73-75.

Lawrinson, W., and Gross, S. (1964). Nuclear arylsulfatase activity in 0 primitive hemic cells. Lab. Invest., 13, 1612-1616.

Lorbacher, P., Yam, L. T., and Mitus, W. J. (1967). Cytochemical demonstration of $\beta$-glucuronidase activity in blood and bone marrow cells. J. Histochem. Cytochem., 15, 680-687.

Melnick, P. J. (1968). Histochemical enzymology of leukemic cells. In Pathology of Leukemia, edited by G. D. Amromin, pp. 128132. Hoeber, New York.

Rosales, C. L., Bennett, J. M., and Rutenberg, A. M. (1966). Histochemical demonstration of leucocyte acid phosphatase in health and in disease. Brit. J. Haemat., 12, 172-176.

Rozenszain, L., Marshak, G., and Efrati, P. (1963). Acid phosphatase activity in normal human blood and bone marrow cells as demonstrated by the azo dye method. Acta haemat. (Basel), 30, 310-316.

Smutka, P., and Brunning, R. D. (1969). An evaulation of nuclear aryl sulfatase activity in acute leukemias. Acta haemat. (Basel), 41, 290-295.

Stuart, J., and Simpson, J. S. (1970). Dehydrogenase enzyme cytochemistry of unfixed leucocytes. J. clin. P.th., 23, 517-521. 